\title{
Particle Filtration Efficiency Testing of Sterilization Wrap
} Masks

\author{
Destiny F. Chau', Patrick O'Shaughnessy' ${ }^{2}$, Michael L. Schmitz' \\ 'Department of Anesthesiology, Arkansas Children's Hospital, University of Arkansas for Medical Sciences, Little Rock, AR, USA; ${ }^{2}$ Department of \\ Occupational and Environmental Health, The University of lowa, lowa City, IA, USA
}

Objectives: Non-traditional materials are used for mask construction to address personal protective equipment shortages during the coronavirus disease 2019 (COVID-19) pandemic. Reusable masks made from surgical sterilization wrap represent such an innovative approach with social media frequently referring to them as "N95 alternatives." This material was tested for particle filtration efficiency and breathability to clarify what role they might have in infection prevention and control.

Methods: A heavyweight, double layer sterilization wrap was tested when new and after 2, 4, 6, and 10 autoclave sterilizing cycles and compared with an approved N95 respirator and a surgical mask via testing procedures using a sodium chloride aerosol for N95 efficiency testing similar to 42 CFR 84.181. Pressure testing to indicate breathability was also conducted.

Results: The particle filtration efficiency for the sterilization wrap ranged between $58 \%$ to $66 \%$, with similar performance when new and after sterilizing cycles. The $\mathrm{N} 95$ respirator and surgical mask performed at $95 \%$ and $68 \%$ respectively. Pressure drops for the sterilization wrap, $\mathrm{N} 95$ and surgical mask were $10.4 \mathrm{mmH}_{2} \mathrm{O}, 5.9 \mathrm{mmH}_{2} \mathrm{O}$, and $5.1 \mathrm{mmH}_{2} \mathrm{O}$, respectively, well below the National Institute for Occupational Safety and Health limits of $35 \mathrm{mmH}_{2} \mathrm{O}$ during initial inhalation and $25 \mathrm{mmH}_{2} \mathrm{O}$ during initial exhalation.

Conclusions: The sterilization wrap's particle filtration efficiency is much lower than a N95 respirator, but falls within the range of a surgical mask, with acceptable breathability. Performance testing of non-traditional mask materials is crucial to determine potential protection efficacy and for correcting misinterpretation propagated through popular media.

Key words: Particle size, Masks, Personal protective equipment, COVID-19, Sterilization

\section{INTRODUCTION}

N95 respirators are essential components of the personal protection equipment (PPE) for healthcare personnel at high-

Received: August 11, 2020 Accepted: November 30, 2020

Corresponding author: Destiny F. Chau

Department of Anesthesiology, Arkansas Children's Hospital, University of Arkansas for Medical Sciences, 1 Children's Way, Slot 677, Little Rock, AR 72202-3500, USA

E-mail: dchau@uams.edu

This is an Open Access article distributed under the terms of the Creative Commons Attribution Non-Commercial License (https://creativecommons.org/licenses/bync/4.0// which permits unrestricted non-commercial use, distribution, and reproduction in any medium, provided the original work is properly cited. risk exposure to the severe acute respiratory syndrome coronavirus 2 (SARS-CoV-2) virus [1]. Unreliable or insufficient procurement of PPE supplies including Unite States National Institute for Occupational Safety and Health (NIOSH)-certified N95 respirators have spurred creative solutions in the quest to protect healthcare workers during the coronavirus disease 2019 (COVID-19) pandemic. One innovative approach includes making masks from surgical sterilization wrap, similar to the University of Florida patented masks [2] that might potentially be reused after autoclave sterilization (Figure 1A). The appeal of sterilization wrap as raw material for mask construction is based on its perceived but unconfirmed ability to provide filtration protection similar to $\mathrm{N} 95$ respirators, its common availability 

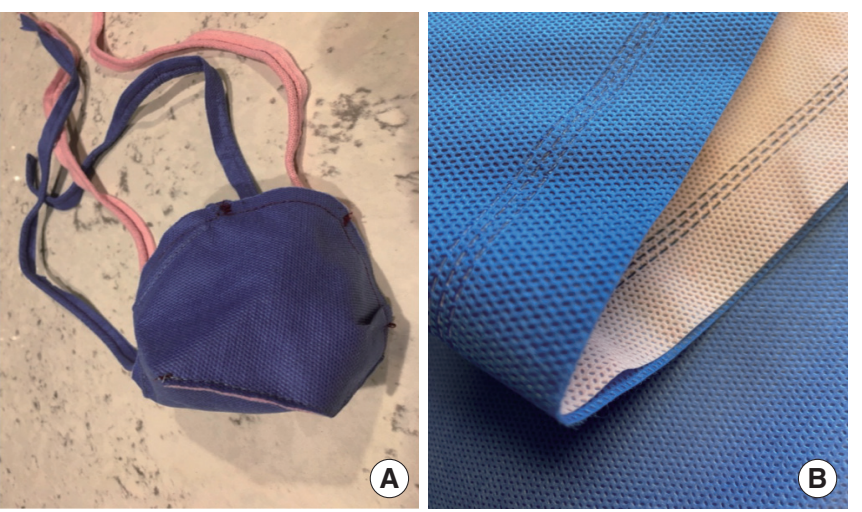

Figure 1. (A) Mask constructed with double layer surgical sterilization wrap. (B) Close up of Medline ${ }^{\mathbb{B}}$ two-color, bonded, double layer heavyweight sterilization wrap (Gem4118T, Medline Industries, Mundelien, IL, USA).

in most hospitals and its lendability for mask-making. Given the difficulty of obtaining sufficient N95 respirators, masks made with sterilization wraps were propagated in social media and public threads as alternatives to N95 masks with circulating pictures of staff producing the masks for potential clinical use. While this idea is resourceful, without objective testing it is unknown whether these masks are indeed as protective as claimed for our frontline workers. Popular media can effectively propagate COVID-19 related disinformation and misinterpretation leading to negative impact [3]. Objective performance testing of non-traditional materials is paramount to clarify what role these new masks have in infection control. Data is lacking regarding the particle filtration efficiency of sterilization wrap when repurposed as masks or respirators.

N95 respirator filtering material and sterilization wraps both contain layers of non-woven polypropylene fibers. In particular, sterilization wrap contains these fibers in layers of meltblown fabric and spunbond material [4] and is described as a three-ply polypropylene sheet or "SMS": spunbond-meltblown-spunbond. The three layers are held together by bonding at many points across the surfaces. The SMS sheet is porous enough to allow ethylene-oxide and steam to pass through the material to the surgical instruments while offering filtration to minimize the passage of pathogens. A common protocol for heavy duty surgical instruments is to wrap them twice sequentially, using two individual sheets of SMS to preserve their sterility in case one sheet is broken. To save one wrapping step, double layer (two SMS sheets) bonded sterilization wraps are also commercially manufactured and are usually bi-colored (Figure 1B) [5]. In contrast to sterilization wraps, the N95 filtering material un- dergoes an added electrostatic charging process that can enhance filtration performance by as much as 10 times to 20 times [6]. Under normal circumstances, both $\mathrm{N} 95$ respirators and sterilization wraps as described are intended for single-use only.

The term "N95" indicates a respirator with a 95\% minimum efficiency when filtering the most penetrating particle sizes (MPPS) of non-oil aerosols, usually reported as $0.3 \mu \mathrm{m}[7,8]$. Due to the intrinsic characteristics of N95 filtering media, particles sizes below and above the MPPS are effectively blocked with greater than $95 \%$ efficiency $[7,8]$. The NIOSH certification process for $\mathrm{N} 95$ respirators requires filtration efficiency of at least $95 \%$ for sodium chloride $(\mathrm{NaCl})$ particles with a size distribution count median diameter of $0.075 \pm 0.020 \mu \mathrm{m}$ and a geometric standard deviation $\leq 1.86$ [9]. Alternatively, sterilization wraps have a manufacturer-stated bacterial filtration efficiency (BFE) rating above 95\% [10] (Supplemental Material 1) using test bacteria of 1-3 $\mu \mathrm{m}$ as indicated by an American Society for Testing and Materials method [11]. The BFE rating of $>95 \%$ efficiency for bacterial filtration can be confused with the $>95 \%$ particle filtration efficiency of an N95 respirator and may lead to the incorrect assumption that they have equivalent filtration efficiency.

This study was conducted to determine whether Medline ${ }^{\circledR}$ Gem4118T sterilization wrap has a particle-capture efficiency similar to $3 \mathrm{M}^{\mathrm{TM}} \mathrm{Vflex}{ }^{\mathrm{TM}} \mathrm{N} 95$ material when using a variant of the NIOSH method. Given the ability of surgical sterilization wrap to withstand the autoclaving process, we also tested for degradation in efficiency after multiple sterilizations. Testing and comparison to a surgical mask (Halyard 47567) was also performed.

\section{METHODS}

We tested the filtration efficiency of a sterilization wrap when new and after autoclave cycles. Samples of Medline ${ }^{\circledR}$ two-color, bonded, double layer heavyweight wrap (Gem4118T; Medline Industries, Mundelien, IL, USA) as well as an N95 respirator (Vflex ${ }^{\mathrm{TM}}$; 3M Corp., Saint Paul, MN, USA) and a surgical mask (Halyard 47567) were subjected to particle efficiency testing using an $\mathrm{NaCl}$ aerosol similar to NIOSH specifications to certify N95 Filtering Facepiece Respirators (42 CFR 84.181) [9] with some exceptions as described below.

An $\mathrm{NaCl}$ aerosol was generated from a 2\% solution applied to a nebulizer (Model 3076; TSI Inc., Shoreview, MN, USA), then dried by passing through a heated steel tube, and charge-neutral- 


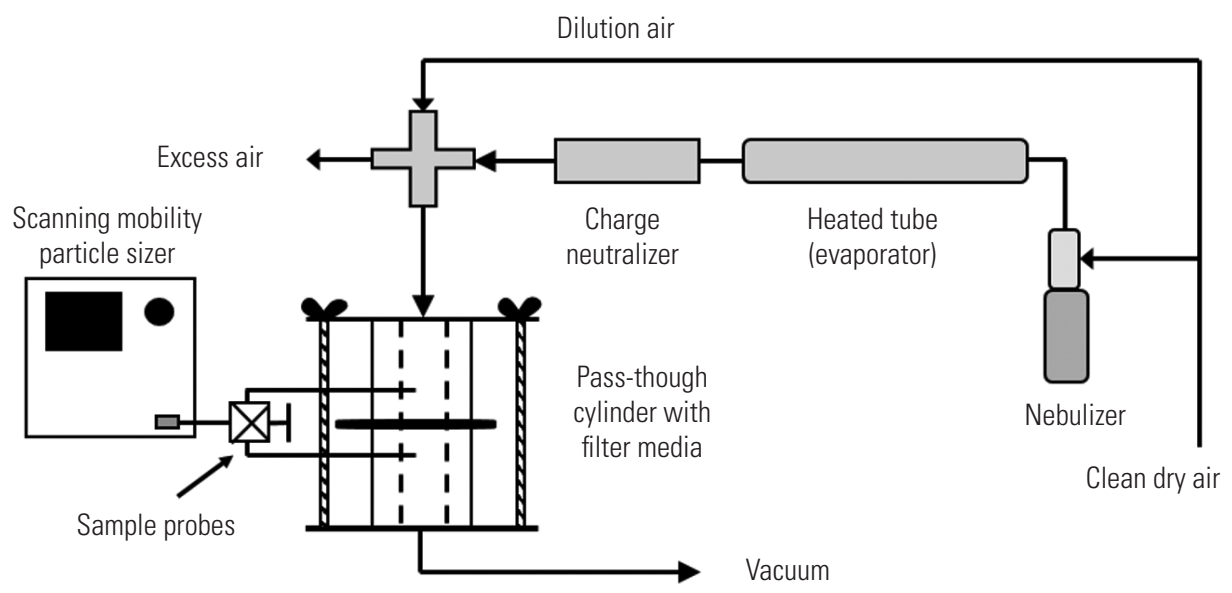

Figure 2. Respirator filtering testing apparatus.

ized with a bi-polar ion source (Model 3088; TSI Inc.) (Figure 2). The generated aerosol was diluted with filtered air resulting in a particle-laden air at $25^{\circ} \mathrm{C}\left(77^{\circ} \mathrm{F}\right)$ and $35 \%$ relative humidity. Aerosol generation was allowed to stabilize for at least five minutes before testing. A column with a 27-mm diameter inner hole was used to test the mask material. The flow rate through the column was adjusted such that the velocity of air drawn through the column would be equivalent to the velocity through the entire mask at $85 \mathrm{~L} / \mathrm{min}$, the standard flowrate for the NIOSH method. Airflow calibration was conducted using a primary calibrator (Gilian Gilibrator 2; Sensidyne, Clearwater, FL, USA) before each test. Aerosol particle count and size distribution were measured with a scanning mobility particle sizer (SMPS) consisting of electrostatic classifier (Model 3080; TSI Inc.) in combination with a condensation particle counter (Model 3785; TSI Inc.). The SMPS counted particles within 103 channels ranging between $7-289 \mathrm{~nm}$. As required by the certification procedure, the $\mathrm{NaCl}$ aerosol is to have a geometric mean diameter of $0.075 \pm 0.020 \mu \mathrm{m}$ and a geometric standard deviation $\leq 1.86$, which was verified with the SMPS prior to a test. As shown in Figure 2, the sample line to the SMPS was evenly split to enable sampling of particles upstream and downstream of the filter media held in the central portion of the sample column. A valve was manually turned to direct flow to the SMPS from the upstream side of the filter media to the downstream side. Particle efficiency was determined as a ratio of the particle concentration downstream $\left(C_{d}\right)$ of the mask sample and concentration upstream $\left(C_{u}\right)$ of the mask sample over the entire range of the $\mathrm{NaCl}$ particle distribution.

$$
E(\%)=\left(1-\frac{C_{d}}{C_{u}}\right) 100
$$

The trials were conducted using the guidance in 42 CFR 84.181 with some exceptions: the mask materials were not preconditioned to $85 \pm 5 \%$ relative humidity at $38.0 \pm 2.5^{\circ} \mathrm{C}$ for $25 \pm 1$ hours and were not preloaded with $\mathrm{NaCl}$ challenge. Particle $C_{u}$ and $C_{d}$ the material were measured with a condensation particle counter associated with the SMPS rather than with the photometers used in the standard filter tester (Model 8130; TSI Inc.). Due to cost limitations, we preliminarily tested only one sample of each item rather than twenty.

Initial pressure drops across the filter media, or "breathing resistance," measurements were also conducted using the sample column. The same holes used to sample upstream and downstream the filter media were connected to a sensitive, calibrated pressure transmitter (Series 646; Dwyer Instruments Inc., Michigan City, MI, USA) that measures in the range of 0-65 $\mathrm{mmH}_{2} \mathrm{O}$ air pressure. The voltage output signal of the transmitter was received by an analog-to-digital converter and read using LabVIEW software (National Instruments, Austin, TX, USA). During a pressure trial, the media was subjected to the same flow rate applied to the mask as when determining particle capture efficiency.

\section{Ethics Statement}

This materials study was exempt from local institutional review board review as human subjects were not involved.

\section{RESULTS}

The particle filtration efficiency results are displayed in Table 1, including the pressure drop across each filter media to evaluate for breathing resistance. 
Table 1. Material particle filtration efficiency and pressure drop

\begin{tabular}{|c|c|c|}
\hline Samples & $\begin{array}{c}\text { Material } \\
\text { efficiency, \% }\end{array}$ & $\begin{array}{l}\text { Pressure drop } \\
\left(\left(\mathrm{mmH}_{2} \mathrm{O}\right)\right.\end{array}$ \\
\hline New sterilizing wrap & 62.4 & 10.4 \\
\hline After 2 autoclave cycles & 66.7 & - \\
\hline After 4 autoclave cycles & 66.3 & - \\
\hline After 6 autoclave cycles & 58.2 & - \\
\hline After 10 autoclave cycles & 61.2 & 10.4 \\
\hline Average, sterilizing wrap samples $(n=5)$ & 63.0 & 10.4 \\
\hline N95 (3M"MVflex $\left.{ }^{\mathrm{TM}}\right)$ & 95.6 & 5.9 \\
\hline Surgical mask (Halyard 47567) & 68.8 & 5.1 \\
\hline
\end{tabular}

Additionally, qualitative fit testing with indicators following the United States Occupational Safety and Health Standards protocol 1910.134 App A [12] were performed by the corresponding author's Occupational Health personnel and found to be successfully passed for all three clinicians tested, each with masks made with the above Medline ${ }^{\circledR}$ Gem4118T sterilization wrap using the University of Florida prototype 2 pattern [2].

\section{DISCUSSION}

The data show that the Medline ${ }^{\circledR}$ Gem4118T sterilization wrap has a substantially lower particle filtration efficiency compared to that of $\mathrm{N} 95$ respirator $\left(3 \mathrm{M}^{\mathrm{TM}} \mathrm{V} \mathrm{flex}^{\mathrm{TM}}\right)$ filtering media. Although the testing protocol followed the NIOSH 42 CFR 84.181 with variations as described could have potentially lowered the measured efficiency, the $3 \mathrm{M}^{\mathrm{TM}} \mathrm{Vflex}{ }^{\mathrm{TM}} \mathrm{N} 95$ respirator sample still showed an efficiency $>95 \%$, suggesting that the modified testing was predictive for the N95 sample. Manufacturer-stated BFE ratings for two widely used brands of sterilization wrap are comparable, citing the Medline Gem4 series mean of $98.8 \%$ (Supplemental Material 1) and the Halyard $\mathrm{H} 600$ median of $99.9 \%$ [10]. Note that Halyard H600 is the former Kimberly-Clark KC600 after product rebranding [13]. It is important to highlight that these efficiency values are not applicable for particle filtration but rather for bacterial filtration. Particles in the size range of bacteria are far more efficiently removed than the much smaller $\mathrm{NaCl}$ particles used in the NIOSH certification process; BFE testing use particles with diameters up to 40 times larger than 0.075 um, so even non-N95 filters may show high efficiency $[8,9]$. We believe this confusion of particle filtration efficiency with BFE contributed to the promotion of sterilization wrap as an N95 substitute material, in addition to its ability to be easily decontaminated with a steam sterilizer that may allow reusability.

The results indicate that surgical sterilization wrap would not be an adequate material for $\mathrm{N} 95$ respirator alternatives. However, its measured particle filtration efficiency falls within the range of surgical masks [14]. We did not verify the thirdparty BFE data provided by the manufacturers [10] (Supplemental Material 1) as the focus of this study was to determine particle filtration efficiency and comparison to $\mathrm{N} 95$ respirators.

Respiratory protection through filtration efficiency can occur only in the setting of a competent face seal [15]. Surgical masks are routinely worn with a loose fit permitting mask leaks during inhalation, as they are not specifically designed for filtration of small particles during wearer inhalation $[14,16]$. A sterilization wrap mask with proper face seal could potentially make it an adequate extender for surgical masks. Regarding airflow resistance for $\mathrm{N} 95$ respirators, it should not exceed $35 \mathrm{mmH}_{2} \mathrm{O}$ during initial inhalation or $25 \mathrm{mmH}_{2} \mathrm{O}$ during initial exhalation per $\mathrm{NIOSH}$ testing stipulations [17]. Note that $\mathrm{NIOSH}$ testing at $85 \mathrm{~L} / \mathrm{min}$ of airflow simulates breathing during moderate to heavy work conditions [18]. Thus, the resistance to breathing of the Medline ${ }^{\circledR}$ Gem4118T sterilization wrap at $10 \mathrm{mmH}_{2} \mathrm{O}$, albeit higher than the resistance for the two other materials, was well below the NIOSH recommended limit as stated above [17]. After 10 autoclave cycles, the measured particle filtration efficiency and pressure drop were essentially unaltered. Note that reusing and repurposing singleuse sterilization wrap through autoclaving is not recommended by the manufacturer. Limitations of this study include limited testing for one type of sterilization material. Testing of other sterilization wrap materials, including those from other manufacturers could expand the results of this study.

Currently, the evolution of the COVID-19 epidemic remains unpredictable with waves of surging cases in different parts of the world. The continuing need for adequate PPE coupled with supply chain instability are still leading to shortages of crucial PPE for the healthcare workers. As non-regulated commercial and homemade PPE are found promoted in popular and social media, research and performance testing of nontraditional materials and equipment are necessary to ensure its proper role in infection prevention and control while correcting disinformation and misinterpretation.

In conclusion, this study provides preliminary data for usage of Medline ${ }^{\circledR}$ Gem4118T sterilization wrap in mask construction as a response to urgent shortages of surgical masks and N95 respirators for protection during the COVID-19 pandemic. 
Results show that the Medline ${ }^{\circledR}$ Gem4118T sterilization wrap mask's particle filtration efficiency is much lower than that of a $\mathrm{NIOSH}$-approved N95 respirator but falls within the range of a surgical mask, with acceptable breathability. Repeated autoclaving did not affect the Medline ${ }^{\circledR}$ Gem4118T sterilization wrap's particle filtration efficiency or resistance to breathing. Performance testing of non-traditional mask materials is crucial to determine potential protection efficacy and for correcting misinterpretation propagated through popular media.

\section{SUPPLEMENTAL MATERIALS}

Supplemental material is available at https://doi.org/10. 3961/jpmph.20.394.

\section{CONFLICT OF INTEREST}

The authors have no conflicts of interest associated with the material presented in this paper.

\section{FUNDING}

This work was supported by the National Institute of Environmental Health Sciences under Grant P30 ES005605.

\section{ACKNOWLEDGEMENTS}

The authors would like to thank Justin Siler and Jordan Ball from the Central Sterile Department at Arkansas Children's Hospital for their assistance in preparing the sterilization wrap samples; Patricia Griffey for her editorial assistance.

\section{AUTHOR CONTRIBUTIONS}

Conceptualization: DFC, PO, MLS. Methodology: PO. Formal analysis: PO. Data curation: DFC, PO, MLS. Funding acquisition: PO. Writing - original draft preparation: DFC, PO, MLS. Writing - review and editing: DFC, PO, MLS.

\section{ORCID}

Destiny F. Chau https://orcid.org/0000-0002-3905-2284

Patrick O'Shaughnessy https://orcid.org/0000-0001-91732722

Michael L. Schmitz https://orcid.org/0000-0001-6625-5389

\section{REFERENCES}

1. Occupational Safety and Health Administration. OSHA factsheet: healthcare workplaces classified as very high or high exposure risk for pandemic influenza [cited 2020 Nov 19]. Available from: https://www.osha.gov/Publications/exposure-riskclassification-factsheet.html.

2. University of Florida. Mask alternative; 2020 [cited 2020 Jul 29]. Available from: https://anest.ufl.edu/clinical-divisions/maskalternative/.

3. Tasnim S, Hossain MM, Mazumder H. Impact of rumors and misinformation on COVID-19 in social media. J Prev Med Public Health 2020;53(3):171-174.

4. Blue Thunder General Topics. An introduction into SMS material [cited 2020 Nov 19]. Available from: https://bluethundertechnologies.com/introduction-sms-material/.

5. Unified Patents. US-5635134-A - method of sterilizing an article [cited 2020 Nov 19]. Available from: https://portal.unifiedpatents.com/patents/patent/US-5635134-A.

6. Juang PS, Tsai P. N95 respirator cleaning and reuse methods proposed by the inventor of the $\mathrm{N} 95$ mask material. J Emerg Med 2020;58(5):817-820.

7. Qian Y, Willeke K, Grinshpun SA, Donnelly J, Coffey CC. Performance of $\mathrm{N} 95$ respirators: filtration efficiency for airborne microbial and inert particles. Am Ind Hyg Assoc J 1998;59(2): 128-132.

8. Bałazy A, Toivola M, Reponen T, Podgórski A, Zimmer A, Grinshpun SA. Manikin-based performance evaluation of $\mathrm{N} 95$ filtering-facepiece respirators challenged with nanoparticles. Ann Occup Hyg 2006;50(3):259-269.

9. U.S. Government Information. 42 CFR 84.181- non-powered air-purifying particulate filter efficiency level determination [cited 2020 Jul 29]. Available from: https://www.govinfo.gov/ content/pkg/CFR-2009-title42-vol1/pdf/CFR-2009-title42vol1-part84-subpartK.pdf.

10. Kimberly-Clark. Bacterial filtration efficiency: Kimguard OneStep* sterilization wrap compared to medline Gemini sterilization wrap [cited 2020 Nov 9]. Available from: https://www. halyardhealth.in/media/287706/h0486_0701_medlinevskc. pdf.

11. U.S. Food \& Drug Administration. Recognized Consensus Standards: ASTM F2101-19 standard test method for evaluating the bacterial filtration efficiency (BFE) of medical face mask materials, using a biological aerosol of Staphylococcus aureus [cited 2020 Jul 29]. Available from: https://www.accessdata. 
fda.gov/scripts/cdrh/cfdocs/cfStandards/detail.cfm?standard identification_no=39935.

12. Occupational Safety and Health Administration. Fit testing procedures (mandatory) [cited 2020 Nov 19]. Available from: https://www.osha.gov/laws-regs/regulations/standardnumb er/1910/1910.134AppA.

13. Halyard Health. Better care deserves a new package design [cited 2020 Nov 19]. Available from: https://www.halyardhealth. com/media/188267/package-change-guide_sterilization_ poster.pdf.

14. Oberg T, Brosseau LM. Surgical mask filter and fit performance. Am J Infect Control 2008;36(4):276-282.

15. Davidson CS, Green CF, Gibbs SG, Schmid KK, Panlilio AL, Jensen PA, et al. Performance evaluation of selected N95 respirators and surgical masks when challenged with aerosolized endospores and inert particles. J Occup Environ Hyg 2013; 10(9):461-467.

16. U.S. Food \& Drug Administration. N95 respirators, surgical masks, and face masks [cited 2020 Nov 19]. Available from: https://www.fda.gov/medical-devices/personal-protectiveequipment-infection-control/n95-respirators-surgical-masksand-face-masks.

17. U.S. Government Information. 42 CFR 84.180 airflow resistance tests [cited 2020 Nov 19]. Available from: https://www.govinfo.gov/content/pkg/CFR-2007-title42-vol1/pdf/CFR-2007-title42-vol1-sec84-180.pdf.

18. Janssen LL, Anderson NJ, Cassidy PE, Weber RA, Nelson TJ. Interpretation of inhalation airflow measurements for respirator design and testing. J Int Soc Respir Prot 2005;22(3/4):122. 